\title{
TREN PERSAINGAN VENDOR ENTERPRISE RESOURCE PLANNING (ERP) DALAM BISNIS GLOBAL
}

\author{
Anang Misbakhul Khoir ${ }^{\mathrm{a}, 1,{ }^{*}}$, Retno Dwi Rahmawati ${ }^{\mathrm{b}, 2}$, Toriq Noor Maulana ${ }^{\mathrm{c}, 3}$, Yusuf Amrozi ${ }^{\mathrm{d}, 4}$, \\ Arista Qiyamullaily, 5

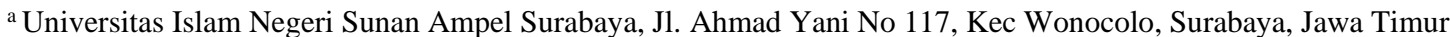 \\ ${ }^{\mathrm{b}}$ Universitas Islam Negeri Sunan Ampel Surabaya, Jl Ahmad Yani No 117, Kec Wonocolo, Surabaya, Jawa Timur \\ c Universitas Islam Negeri Sunan Ampel Surabaya, Jl Ahmad Yani No 117, Kec Wonocolo, Surabaya, Jawa Timur \\ d Universitas Islam Negeri Sunan Ampel Surabaya, Jl Ahmad Yani No 117, Kec Wonocolo, Surabaya, Jawa Timur \\ e Universitas Islam Negeri Sunan Ampel Surabaya, Jl Ahmad Yani No 117, Kec Wonocolo, Surabaya, Jawa Timur \\ 1 aafecoc@gmail.com*; ${ }^{2}$ retnodwi1125@gmail.com; ${ }^{3}$ toriqmaulana01@ gmail.com, ${ }^{4}$ yusuf.amrozi@gmail.com \\ * corresponding author
}

ARTICLE INFO

Keywords

ERP

Perusahaan

Vendor

Bisnis global

\section{ABSTRACT}

There are still some companies that do not apply ERP with company/organizational processing. ERP implementation is very important for companies, therefore it is necessary to find the right vendor to be applied to the company. So this research is needed to find out which vendors are most widely used in global business. The method used in this research is to find data in the literature and related journals. This research results in an ERP vendor that relatively dominates the market is SAP.

\section{Pendahuluan}

Selama bertahun - tahun, lingkungan bisnis mengalami laju perubahan yang meningkat. Perusahaan di seluruh dunia berusaha memenuhi kebutuhan para konsumen dan meraih peluang pasar yang lebih tinggi. Perusahaan yang sukses biasanya menyadari kebutuhan akan sistem yang terintegrasi dapat meningkatkan kinerja, kepuasan pelanggan, kualitas, serta keuntungan bagi perusahaan.

Perkembangan teknologi informasi yang semakin maju membuat setiap perusahaan berpeluang untuk menggunakan teknologi sebagai alat yang digunakan untuk menunjukkan keunggulan bersaing dari perusahaan lainnya. Teknologi yang saat ini digunakan oleh berbagai perusahaan untuk unjuk gigi di dunia perbisnisan adalah teknologi dari Enterprise Resource Planning (ERP) ini.

Pada masa sekarang persaingan bisnis menjadi lebih ketat. Perusahaan harus bisa mengikuti perubahan berbagai tren teknologi. Menjalankan bisnis dengan metode lama hanya akan membuat perusahaan akan jauh tertinggal dengan yang lainnya. dengan Enterprise Resource Planning (ERP) berbagai operasional bisnis yang kompleks dapat disederhanakan sehingga dapat mengoptimalkan produktivitas perusahaan, meningkatkan efisiensi, serta menghemat biaya[1].

Didalam suatu perusahaan jika sistem informasi berdiri sendiri dan tidak saling integrasi antara satu dengan yang lainnya, sehingga informasi yang didapatkan tidak akan maksimal bagi pengambilan keputusan dalam perusahaan tersebut. Jadi diperlukannya sebuah sistem yang dapat menyatukan berbagai sistem informasi dalam perusahaan tersebut[2]. Hal ini dapat terwujud melalui adanya sistem Enterprise Resource Planning atau yang biasa disingkat dengan ERP.

Enterprise Resource Planning (ERP) adalah software lintas fungsi terpadu yang merekayasa ulang proses manufaktur, distribusi, keuangan, sumber daya manusia, dan proses bisnis dasar lainnya dari suatu perusahaan untuk memperbaiki efisiensi, kelincahan, dan profitabilitasnya[3]. Teknologi ERP 
dapat mengintegrasikan fungsi marketing, fungsi produksi, fungsi logistik, fungsi finance, fungsi sumber daya manusia, dan fungsi lainnya[4].

Perencanaan sumberdaya perusahaan atau Enterprise Resource Planning (ERP) adalah aplikasi komputer yang menyatukan sistem informasi yang mencakup berbagai fungsi utama perusahaan, seperti fungsi keuangan, produksi, pemasaran, sumber daya manusia dan lain sebagainya[5]. Selain itu, ERP sendiri juga merupakan sebuah sistem komputer terpadu yang menyatukan seluruh departemen yang berbeda pada sebuah perusahaan dengan mengakomodasi semua kebutuhan spesifik dari setiap departemen. Setiap departemen masih memiliki sistem sendiri, tetapi semua sudah terintegrasi satu sama lain, sehingga dapat memantau suatu permasalahan yang terjadi secara teratur.

Berdasarkan definisi tersebut, dapat disimpulkan pengertian ERP adalah suatu perangkat lunak yang mengintegrasi berbagai sistem informasi di dalam perusahaan. Dengan adanya sistem ini, kinerja perusahaan akan meningkat dan semua prosesnya menjadi lebih efektif dan efisien sehingga pendapatan perusahaan pun ikut meningkat dan resiko dari kesalahan yang dapat ditimbulkan pun akan menjadi lebih berkurang.

Perusahaan besar di seluruh dunia mulai mengimplementasikan sistem ERP sejak tahun 1990 sebagai kerangka kerja konseptual dan katalis untuk merekayasa ulang proses bisnis. ERP bertindak sebagai tulang punggung lintas fungsional perusahaan yang mengintegrasikan dan mengotomatisasikan banyak proses internal dan sistem informasi. Sistem ERP dibagi atas beberapa sub sistem yaitu sistem financial, sistem distribusi, sistem manufaktur, dan sistem human resource[5].

Enterprise Resource Planning (ERP) memiliki berbagai macam modul yang dapat diimplementasikan ke berbagai bidang di sebuah perusahaan. Apalagi saat ini vendor - vendor juga banyak menggunakan sistem Enterprise Resource Planning (ERP) dalam menjalankan usahanya. Dari sistem Enterprise Resource Planning ini masalah yang dihadapi oleh vendor - vendor seperti dalam masalah penjualan, masalah sales dari produk - produk yang dihasilkan belum maksimal, masalah dalam hasil pelaporan yang kurang detail hingga dibutuhkannya peningkatan kinerja pada perusahaan sehingga dapat memudahkan perushaan untuk mengambil informasi dengan cepat dan tepan ini dapat tertangani dengan baik oleh sistem ERP [15].

Di zaman modern ini, persaingan pasar semakin kompetitif, konsumen yang menjadi semakin kritis menuntut perusahaan agar bisa memenuhi kebutuhan konsumen secara akurat dan cepat. Sehingga penerapan perangkat lunak Enterprise Resource Planning sudah menjadi kebutuhan dasar dalam sistem manajemen perusahaan. Perusahaan akan sulit untuk memenuhi kebutuhan pasar dan berkembang jika masih menggunakan sistem manajemen lama yang manual. Proses integrasi dan otomasi data menjadi lebih mudah dengan adanya penerapan sistem ERP pada perusahaan[16].

Mengingat pentingnya sistem Enterprise Resource Planning (ERP), dalam memilih ERP dan juga vendor menjadi perhatian tersendiri. Perusahaan - perusahaan di bidang IT berlomba - lomba dalam mengembangkan sistem Enterprise Resource Planning yang menjadikan lebih banyak pilihan bagi para pebisnis. Sehingga perusahaan harus benar - benar selektif dalam memilih aplikasi dan vendor ERP. Terdapat banyak pilihan vendor yang berasal dari dalam negeri maupun asing. Tentu semua berharap dengan ERP akan dapat meningkatkan produktivitas dan profit.

Perbandingan serta riset sangat penting untuk dilakukan untuk menemukan sistem ERP yang tepat untuk perusahaan. Dalam mengimplementasikan sistem Enterprise Resource Planning terdapat juga adanya resiko kegagalan dalam mengimplementasikan sistem ERP dalam suatu perusahaan. Alasan kegagalan hampir setiap kasus dari pengimplementasian sistem disebabkan oleh para profesional TI dan manajer dari perusahaan yang menganggap enteng kompleksitas perencanaan, pengembangan, serta pelatihan yang dibutuhkan untuk mempersiapkan penerapan sistem Enterprise Resource Planning (ERP) yang baru.

Vendor Enterprise Resource Planning yang bagus pasti sudah berpengalaman dan mendapatkan banyak achievement yang dapat dijadikan sebagai bahan pertimbangan dalam memilih. Namun 
vendor ERP yang berpengalaman tentunya memiliki harga yang lebih mahal dan akan memakan lebih banyak anggaran perusahaan. Jadi pahami dan lakukan riset mendalam mengenai sistem ERP, manfaat yang diterima oleh perusahaan, dan modul - modul yang tersedia di dalamnya. Jika sistem ERP yang dipilih tidak mengalami kegagalan atau tidak sesuai dengan yang diharapkan, maka waktu dan biaya yang telah tercurahkan akan menjadi percuma.

\section{Metodologi Penelitian}

Metode penelitian ini menggunakan metode penelitian kualitatif. Metode kualitatif merupakan prosedur riset yang memanfaatkan data deskriptif, berupa kata-kata tertulis atau lisan dari orang atau subjek yang diamati. Kegiatan pokok dalam penelitian ini adalah mendeskripsikan dan menganalisis secara intensif tentang segala fenomena sosial yang diteliti, yaitu mengenai tren persaingan vendor Enterprise Resource Planning dalam bisnis global. Penelitian ini menggunakan sumber data yang diambil dengan menelusuri sumber-sumber literatur dan jurnal-jurnal yang berkaitan dengan penelitian ini.

\section{Hasil dan Pembahasan}

\subsection{Terminologi ERP}

Enterprise Resource Planning (ERP) merupakan konsep untuk mengelola sumber daya dan merencanakan perusahaan seperti mesin, suku cadang, manusia, dana, material, waktu, dan kapasitas - kapasitas yang membuat pengaruh menjadi luas[6]. Dari konsep inilah perusahaan, dapat mengotomasi dan mengintegrasi proses bisnisnya dengan baik dan benar didukung juga oleh infrastruktur yang memadaimulai dari infrastruktur komputer dan aplikasi, baik software maupun hardware yang dapat mengolah data informasi perusahaan agar mudah dipergunakan. Hal itu terjadi agar perusahaan mendapatkan hasil yang maksimal dengan menghasilkan nilai - nilai plus dalam setiap pihak pihak yang berkepentingan dalam perusahaan tersebut.

Enterprise Resource Planning (ERP) merupakan suatu perangkat lunak software aplikasi yang terintegrasi dengan baik dan digunakan secara luas dalam Organisasi bisnis[7]. Aplikasi inilah yang menjalankan fungsi - fungsi operasional dalam bisnis dan juga meningkatkan efektivitas dan efisiensi dari sebuah perusahaan. Dari aplikasi ini juga muncul modul - modul ERP yang dirancang sesuai dengan proses bisnisnya dari hulu ke hilir dan terintegrasi dalam basis datanya untuk dipergunakan dalam fungsi - fungsi operasionalnya.

\subsection{Macam - Macam Vendor ERP}

1. Odoo

Fabian Pinckaers pada tahun 2005, pendiri dan CEO Odoo saat ini, awalnya mengembangkan produk perangkat lunak pertamanya bernama TinyERP. Tiga tahun kemudian, TinyERP diubah namanya menjadi OpenERP yang mulai berkembang pesat setelah perubahan namanya. Kemudian di tahun 2014, OpenERP mengubah namanya kembali menjadi Odoo, guna memperluas citranya di pasar internasional. Dalam rangka membantu meningkatkan efisiensi dan efektivitas bisnis perusahaan, Odoo menghadirkan sebuah aplikasi ERP yang menawarkan berbagai solusi dalam bisnis melalui perancangan dan pengimplementasian sistem IT berdasarkan kebutuhan bisnis melalui Odoo Enterprise[8].

Odoo merupakan open source ERP yang memiliki fitur dalam manajemen proyek, manajemen hubungan pelanggan, sumber daya manusia, penjualan, akuntansi, manufaktur dan inventarisasi. Odoo semakin berkembang dan diminati[9]. Menurut [9], Odoo yang mudah untuk dikustomisasi 
menunjukkan kemampuan adaptasi yang baik sehingga banyak diminati oleh berbagai perusahaan. Tampilan Odoo dapat disebut menarik dan mudah dipahami dibandingkan tampilan - tampilan ERP lainnya. Sebagai open source ERP, biaya implementasi Odoo dinilai dapat dikatakan rendah karena tidak adanya biaya lisensi.

Penggunaan Odoo pun sudah mencapai lebih dari 4.500 .000 pengguna yang berada di seluruh dunia, baik perusahaan kecil sampai perusahaan besar. Contoh contoh perusahaan yang menggunakan Odoo adalah Abuba Steak, Meat 'N' Fresh, Solar Time, A-Line, dan banyak lagi.

2. SAP

System Application and Processing atau disingkat menjadi SAP memiliki kantor pusat di Walldorf, Jerman. Pada tanggal 1 April 1972, Dientmar Hopp, Hasso Platter, Claus Wellenreuther, Klaus Tschira, dan Hans Werner Hector memulai perusahaan System Analyse Programmentwicklung. Ide mereka adalah membuat perangkat lunak perusahaan standar yang mengintegrasikan semua proses bisnis dan memungkinkan pemrosesan data secara real time. Pada tahun 1975, mereka telah membangun aplikasi untuk akuntansi keuangan (RF), verifikasi faktur, dan manajemen persedian (RM). Perusahaan mulai mengembangkan generasi kedua dari perangkat lunaknya yaitu $\mathrm{R} / 2$ pada tahun 1979.

Kisah sukses SAP R/3 dimulai pada tahun 1922, dengan perangkat lunak client-server memperlancar jalan menuju ekonomi global. Menanggapi internet dan ekonomi baru SAP meluncurkan strategi mysap.com pada tahun 1999. Sepuluh tahun kemudian, perusahaan bercabang menjadi 3 pasar masa depan yaitu teknologi seluler, teknologi basis data, dan cloud. Untuk menjadi pemain kunci dalam domain baru ini, SAP mengakuisisi beberapa pesaingnya, termasuk Sybase, Ariba, Concur, Fieldglass, dan lain - lainnya.

Pada tahun 2011, mulai menggunakan database dalam memori SAP HANA. Analisis data yang biasanya memakan waktu berhari - hari atau bahkan berminggu - minggu, kini diselesaikan dalam hitungan detik. Empat tahun kemudian, SAP meluncurkan SAP S/4HANA. Saat ini, SAP membangun solusi untuk Internet of Things dan pembelajaran mesin, untuk analisis kompleks dan blockchain[6].

Pada awalnya SAP digunakan oleh perusahaan besar setingkat multinasional, namun sekarang SAP juga menawarkan produk untuk perusahaan kecil dan menengah dengan produk yang dinamakan SAP Business One dan SAP All In-One[11].

SAP memiliki lebih dari 238 juta pengguna saat ini, SAP mengoperasikan 70 pusat data di 37 lokasi di 17 negara[10]. Contoh perusahaan yang mengimplementasikan SAP adalah Astra International, Toyota Astra Motor, Bentoel Prima, United Tractor, Pertamina, Telkomsel, Auto 2000, Blue Bird, dan beberapa perusahaan lain[6].

\section{NetSuite}

NetSuite didirikan pada tahun 1998 oleh Evan Goldberg yang menawarkan perangkat lunak akuntansi web host. NetSuite memelopori revolusi Cloud Computing, mendirikan perusahaan pertama di dunia yang didedikasikan untuk memberikan aplikasi bisnis melalui internet. Pada November 2016, Oracle telah menyelesaikan proses akuisisi terhadap NetSuite. Saat ini NetSuite menyediakan paket keuangan berbasis cloud dan mempunyai lebih dari 24.000 pelanggan di lebih dari 200 negara dan wilayah[12]. Contoh perusahaan yang mengimplementasikan NetSuite adalah SunMoon.

\section{Ecount ERP}

Ecount ERP didirikan pada tahun 1999, kami mengembangkan salah satu dari sistem ERP berbasis cloud pertama yang tersedia untuk bisnis kecil di Korea Selatan. Di tahun 2012, kami secara formal memperluas pasar dengan membuka kantor di Amerika Serikat. Pada tahun 2013, Ecount juga memutuskan untuk memperluas pasar ke Tiongkok. Jumlah pengguna Ecount sekitar 200.00 dengan 
customer 22.000. Ecount ERP menyediakan pengelolaan persediaan, produksi, penjualan, pembelian, akuntansi, dan penggajian[13].

\section{Sage Intacct}

Intacct didirikan oleh Odysseas Tsatalos dan David Thomas pada tahun 1999 sebagai salah satu aplikasi akuntansi pertama untuk cloud. Intacct telah memantapkan dirinya sebagai penyedia perangkat lunak manajemen keuangan cloud terkemuka untuk usaha kecil dan menengah. Pada tahun 2017, Sage mengumumkan akuisisi Intacct sebagai landasan transformasi berkelanjutan menjadi perusahaan SaaS yang hebat. Sage intacct memiliki sekitar 14.000 pelanggan[14].

Berdasarkan data tahun 2005, maka sistem ERP yang mempunyai penetrasi pasar terbesar adalah SAP, yang secara detail dapat dilihat dalam tabel 1 .

Tabel1.Pangsa pasar ERP tahun 2005 berdasarkan Gartner Dataques

\begin{tabular}{ccccc}
\hline Rank & Vendor & Revenue (millions \$) & Market share (\%) & Year \\
\hline 1 & SAP & 4726 & 28.7 & 2005 \\
\hline 2 & Oracle Applications & 1674 & 10.2 & 2005 \\
\hline 3 & The Sage Group & 1221 & 7.4 & 2005 \\
\hline 4 & Microsoft Dynamics & 616 & 3.7 & 2005 \\
\hline 5 & SSA Global Tecnologies & 464 & 2.8 & 2005 \\
\hline 6 & Unit 4 Agresso & 465.2 & unknown & 2005 \\
\hline 7 & Lawson Software & 390.8 & unknown & 2006 \\
\hline 8 & Epicor & 384.1 & unknown & 2006 \\
\hline 9 & Visma & 305.5 & unknown & 2005 \\
\hline 10 & Industrial and Financial System & 288 & unknown & 2005 \\
\hline 11 & QAD & 225 & unknown & 2006 \\
\hline 12 & Ramco System & 60.1 & unknown & 2006 \\
\hline 13 & NetSuite & 40 & unknown & 2004 \\
\hline 14 & SIV.AG & 18.7 & unknown & unknown \\
\hline
\end{tabular}

\subsection{Manfaat ERP}

Pengaplikasian ERP sangat membantu di industri karena sistem kerja dari manufaktur yang berfokus terhadap pekerjaan mesin sehingga harus mengurangi segala tindakan yang memakan biaya, seperti penyimpanan data dengan kertas harus dihilangkan. Manfaat yang dapat dicapai ketika menerapkan ERP dalam perusahaan diantaranya adalah sebagai berikut[5],

1. Menyederhanakan berbagai aktivitas operasional yang memakan banyak tenaga dan waktu karena semuanya dapat dilakukan secara otomatis.

2. Data yang telah dimasukkan ke dalam sistem ERP membuat kolaborasi antar departemen akan berjalan lancar, karena tiap - tiap departemen dapat mengakses data dari departemen lainnya.

3. Karena sebagian besar aktivitas operasional dilakukan secara otomatis, sehingga berbagai kendala, gangguan, dan kerusakan dapat diantisipasi dengan baik. Pekerjaan yang kompleks dapat diselesaikan dengan lebih cepat, sehingga dapat mengurangi biaya tenaga kerja.

4. Seluruh data disimpan dalam sistem terpusat sehingga titik akses dapat dimonitor dengan ketat dan keamanannya terjaga. 
5. Penting bagi bisnis untuk mendapatkan laporan yang lengkap, konsisten, serta real time untuk membuat prakiraan yang akan mempengaruhi keputusan yang akan diambil dan ERP mampu untuk memfasilitasi semua hal tersebut.

\subsection{Kelebihan dan Kekurangan ERP}

Sebaik dan secanggih apapun sistem dan teknologi, tidak dapat dipungkiri pastinya memiliki kelebihan dan kekurangan. Adapun beberapa keuntungan dari pengguna sistem informasi terpadu dalam konsep ERP ini antara lain dapat disebutkan sebagai berikut[6]:

1. Sistem terintegrasi di dalam perusahaan, sehingga proses dan pengambilan keputusan dapat dilakukan secara efektif dan efisien. ERP juga memungkinkan melakukan integrasi secara global. Halangan yang tadinya berupa perbedaan valuta, perbedaan bahasa, dan perbedaan budaya dapat dijembatani secara otomatis, sehingga data dapat terintegrasi.

2. Tidak hanya memasukan data dan orang tetapi juga menghilangkan kebutuhan pemutakhiran dan sinkronisasi banyak sistem komputer terpisah.

3. Membantu melancarkan pelaksanaan manajemen supply chain dengan kemampuan memadukannya.

Sedangkan kekurangan vendor antara lain sebagai berikut[5]:

1. Biaya yang mahal

2. Ketergantungan pada satu vendor tertentu

3. Aplikasi yang ditangani sangat kompleks.

\subsection{Faktor - Faktor Yang Perlu Dipertimbangkan Saat Memilih Vendor ERP}

Terdapat banyak pilihan vendor ERP di luar sana yang menawarkan berbagai solusi yang serupa. Jadi dalam memilih vendor ERP perlu memperhatikan berbagai faktor yang mempengaruhi dalam pemilihan ERP. Berdasarkan penelitian yang dilakukan oleh Setyawan terdapat beberapa faktor yang perlu untuk dipertimbangkan diantaranya sebagai berikut[6],

1. Beberapa besar transaksi atau proses bisnis yang terkait dalam proses otomasi ini. Semakin besar dan semakin kompleks suatu proses bisnis maka sistem ERP yang akan digunakan harus memenuhi kebutuhan tersebut terutama reliabilitasnya. Ini akan terlihat dari besaran platform perangkat keras yang digunakan.

2. Pengalaman vendor dalam implementasi dengan perusahaan yang mempunyai proses bisnis yang sama akan sangat penting. Referensi tersebut dapat digunakan sebagai pembanding.

3. Kemampuan vendor/developer dalam mengenal proses bisnis, ketajaman dalam pendefinisian proyek serta mengenal titik - titik kritis saat implementasi.

4. Sebuah perangkat lunak haruslah mempunyai skalabilitas dan kontinuitas support yang baik pada kebanyakan vendor. Untuk itu perlu sekali dalam kontrak pemeliharaan dicantumkan klausul penalti apabila terjadi kegagalan support. Tentunya lingkup support itu sendiri perlu didefinisikan dengan jelas dan tegas.

\section{Kesimpulan}

Dari pembahasan diatas didapatkan bahwa vendor ERP adalah Odoo, SAP, Oracle, Ecount, dan Sage Intacct. Dari ke 5 vendor tersebut yang relatif menguasai pasar ERP adalah SAP karena selain SAP mempunyai pengalaman yang lebih lama dalam bidang ini, juga karena data yang disajikan pada SAP bersifat real time. Sehingga perusahaan akan mendapatkan informasi akurat dan terbaru, selain itu informasi tersebut akan mudah untuk diakses kapan saja dan dimana saja. Jika ada tren pasar yang sedang berubah, SAP dapat membantu perusahaan dalam menganalisa pelanggan yang berubah 
dimana. SAP tidak hanya tersedia untuk perusahaan besar tetapi juga perusahaan menengah ke bawah.

\section{Daftar Pustaka}

[1] W. Agus Winarno, "Kesuksesan dan Kegagalan Implementasi Sistem ERP: Apakah kesalahan peranti lunak.

[2] R. Kenge, Z. Khan, "A Research study in the ERP and Current Trends in ERP," vol. 8 go 7 International Journal of Management, 2020, pp. 35.

[3] J. A. O’Brien, G. M. Marakas, “ Introduction to Information System 13e,” McGrawHill Irwin, 2013.

[4] Z. J. Husada Tarigan, "Pengaruh Implementasi Erp Terhadap Product Diffrentiation Dan Cost Leadership Dalam Meningkatkan Kinerja Perusahaan,” Jurnal Manajemen Pemasaran, Vol. 4 No. 1, 2009.

[5] Suryalena, "Enterprise Resource Planning (ERP) Sebagai Tulang Punggung Bisnis Masa Kini," Jurnal Aplikasi Bisnis, Vol. 3 No. 2, 2013.

[6] S. Wibisono, "Enterprise Resource Planning (ERP) Solusi Sistem Informasi Terintegrasi," Jurnal Teknologi Informasi DINAMIK, Vol. 10 No. 3, 2005.

[7] T. Q. Ferbia, E. T. Kirana, J. C. Patty, “Analisis Penggunaan Sistem ERP Untuk Transformasi Proses Bisnis Studi Kasus: Supermarket Bangunan Dan Furniture,” Jurnal Jutim, Vol. 3 No. 22018.

[8] “The Odoo Story,” https://www.odoo.com/id_ID/blog/odoo-news-5/the-odoo-story-56, diakses pada tanggal 4 juni 2021 pukul 17.23.

[9] Limantara, N., \& Jingga, F. “Open Source ERP: ODOO Implementation at Micro Small Medium Enterprises: (A Case Study Approach at CV. XYZ In Module Purchasing And Production)”. International Conference on Information Management and Technology (ICIMTech). 2017.

[10] "History SAP," https:/www.sap.com/about/company/history.html?pdf-asset=70eee289-847d-0010-87a3c30de2ffd8ff\&page=1, diakses pada tanggal 4 juni 2021 pada pukul 18.35.

[11] Rayung. W, "Perbandingan Aplikasi ERP Pada Perusahaan Skala Kecil dan Menengah Dengan Menggunakan Parameter Produktivitas Bisnis,” Jurnal Ilmiah Faktor Exacta, Vol No. 1 Maret 2010.

[12] https://www.netsuite.com/portal/aboutus.shtml, diakses pada tanggal 4 juni 2021, pada pukul 19.03.

[13] “Sejarah Ecount Inc.," https://www.ecount.com/id/ecount/company/about-us?p=T2, diakses pada tanggal 4 juni 2021, pada pukul 19.29.

[14] “The Sage Intacct Story," https://www.sageintacct.com/company, diakses pada tanggal 4 juni 2021, pada pukul 19.51 .

[15] D.M. Sagala, L. Rahmadani, Y. Rahmadani, E.S. Wahyuningsih, A. Auliyah, N.F. Lawita,"Penerapan Database pada Perusahaan (Studi Penerapan ERP pada PT. Sinar Sosro)," Jurnal Pendidikan Tambusai, Vol. 5 No. 2, Tahun 2021.

[16] R.N. Antika, Fawaz, C. Rahardjo, M. Saleh, “Analisis Penerapan Modul Erp Pada Perusahaan Sektor Ub (Studi Literature: PT. Domusindo Perdana Dan PT. Jepe Press Media Utama Surabaya),” Proceeding Seminar Nasional Ilmu Komputer, Vol. 1 No. 1, 2021. 